\title{
Announcement
}

\section{Honorary Doctorate Awarded to Thomas Karger}

In November 1993, Thomas Karger, current president of S. Karger Publishers, was awarded an honorary doctorate by the Medical Faculty of the University of Basel. In their laudatory address the Faculty acknowledged Dr. Kargefs achievements as founder and publisher of a large number of internationally renowned journals covering a wide range of medical and scientific fields, as well as his generous financial support of young medical scientists. Recognition was also given to his successful organization of international symposia devoted to current interdisciplinary topics in biomedical research, which has enhanced the reputation of Basel and its university as centers of scientific achievement.

As early as 1972 Thomas Karger received his first honorary doctorate from the University of Hamburg in recognition of his efforts on behalf of medical science. On being asked how it felt to receive such an honour for the second time, Dr. Karger replied, 'This is cer-

tainly a great honour. I am very happy that such high recognition has been accorded to the work I have done. But I must also stress the fact that all this could never have been achieved had it not been for the support of my wife, family and employees and - last but not least - of the scientists all over the world who have collaborated with my company. I would like to express my deepest gratitude to everyone involved.'

In 1990, the publishing house celebrated its 100th anniversary as an independent family-owned company. With the support of his two sons and one of his daughters, the fourth generation of a family of publishers, Thomas Karger is confident that he will be able to maintain this independence and continue his service to the scientific community by providing the vital information link between medical research and clinical practice. 